\title{
Perinatal diagnosis and management of congenital bronchial stenosis or atresia: 4 cases
}

\author{
Anna Poupalou, MD, Concetta Varetti, MD, Gerome Lauron, MD, Henri Steyaert, MD, and \\ Jean-Stephane Valla, MD, Nice, France
}

Congenital bronchial atresia or stenosis (CBAS) is a benign bronchopulmonary anomaly characterized by blindly terminating or significantly stenosed segmental or lobar bronchus, hyperinflation of the adjacent lung parenchyma, and mucusfilled bronchocele. ${ }^{1}$ CBAS is usually diagnosed in the second or third decade of life; neonatal presentation is extremely rare. ${ }^{2}$ Prenatal diagnosis remains difficult. ${ }^{3}$ In this article, we describe the clinical features, radiologic findings, and surgical treatment of 4 cases of CBAS presented as lung malformation in prenatal ( 3 cases) or postnatal investigation.

\section{Case Reports \\ Case 1}

A white boy was delivered vaginally at 40 weeks of gestation with a birth weight of $3230 \mathrm{~g}$ and Apgar scores of 10/10. Massive enlargement of the right lung and a mediastinal shift to the left was detected on routine ultrasound at 22 weeks of gestation. However, the size of the right lung gradually decreased during the pregnancy, and the mediastinal shift resolved. The mother had had a medical treatment for malaria in the first trimester of pregnancy.

The baby was placed on a respirator a few hours after birth because of respiratory distress. A chest radiograph after birth demonstrated a distended right lung and a mediastinal shift to the left (Figure 1). Enlargement and hyperlucency of the right lung were gradually progressing. A flexible bronchoscopy showed a severe juxtacarinal right main bronchus stenosis. Spiral chest computed tomography with multiplanar reconstruction confirmed the bronchoscopic findings (Figure 2, A): the right main bronchus stenosis was $5 \mathrm{~mm}$ long, with a diameter of 0.8 to $1 \mathrm{~mm}$ (Figure 3 ). Scintigraphy demonstrated markedly decreased ventilation and perfusion of the affected lung (18\% and $15 \%$, respectively).

The child was dismissed from the hospital after stabilization. After 4 failed attempts at bronchoscopic dilation, he un-

\footnotetext{
From the Department of Pediatric Surgery, Fondation Lenval pour Enfants, Nice, France.

Disclosures: Authors have nothing to disclose with regard to commercial support.

Received for publication March 15, 2010; revisions received Aug 18, 2010; accepted for publication Sept 9, 2010.

Address for reprints: Anna Poupalou, MD, Department of Pediatric Surgery,

Fondation Lenval pour Enfants, 57 Avenue de la Californie, Nice, France

(E-mail: apoupalou@gmail.com).

J Thorac Cardiovasc Surg 2011;141:e11-4

$0022-5223 / \$ 36.00$

Copyright (c) 2011 by The American Association for Thoracic Surgery

doi: 10.1016/j.jtcvs.2010.09.046
}

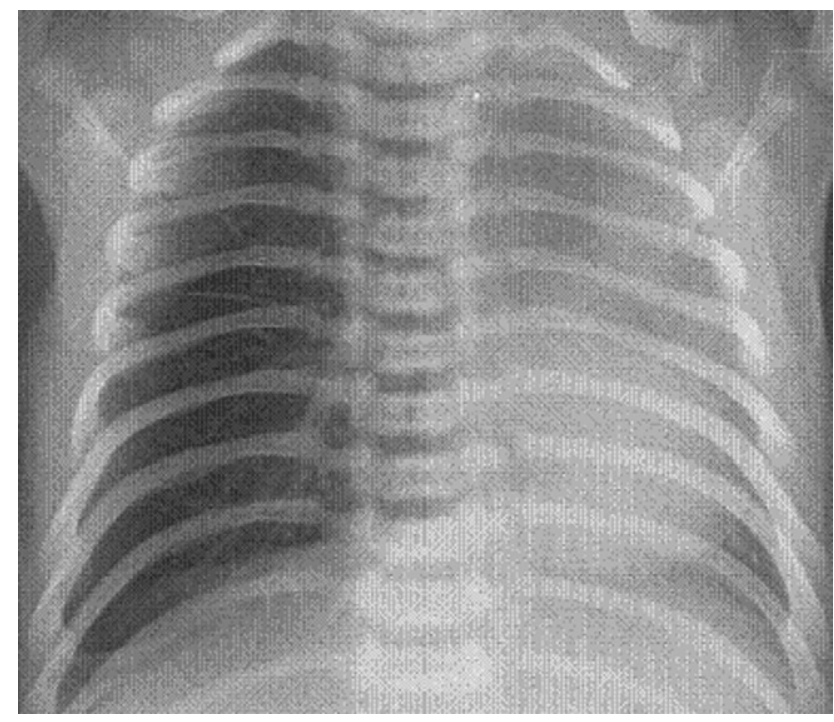

FIGURE 1. Plain anteroposterior chest radiograph after birth (Case 1) demonstrated hyperinflation of the large right lung and mediastinal shift to the left.

derwent bronchoplasty at $8 \frac{1}{2}$ months of age through a transaxillary thoracotomy. The exposure of the anterior surface of the carina and right main bronchus was then completed after selective intubation of the left bronchus. A resection of the stenotic segment and a tension-free anastomosis with interrupted sutures (Vicryl 5/0) were performed (Figure 4). An intraoperative bronchoscopy confirmed the patency of the anastomosis (Figure 2, B). The child was extubated in the operating room.

The resected specimen showed that the central part of the right main bronchus was markedly stenotic, fibrotic, and inflamed. The postoperative course was uneventful. The size of the right lung gradually decreased, and the mediastinal shift resolved during the 15-month follow-up period. Scintigraphy demonstrated markedly improved ventilation and perfusion of the affected lung ( $54 \%$ and $40 \%$, respectively).

\section{Case 2}

A male newborn was referred because a right intrapulmonary mass was revealed on routine ultrasound at 22 weeks of gestation. A bronchopulmonary sequestration was suspected. The presence of the mass was confirmed by a postnatal chest radiograph and computerized tomography. Three-dimensional computed tomography demonstrated 

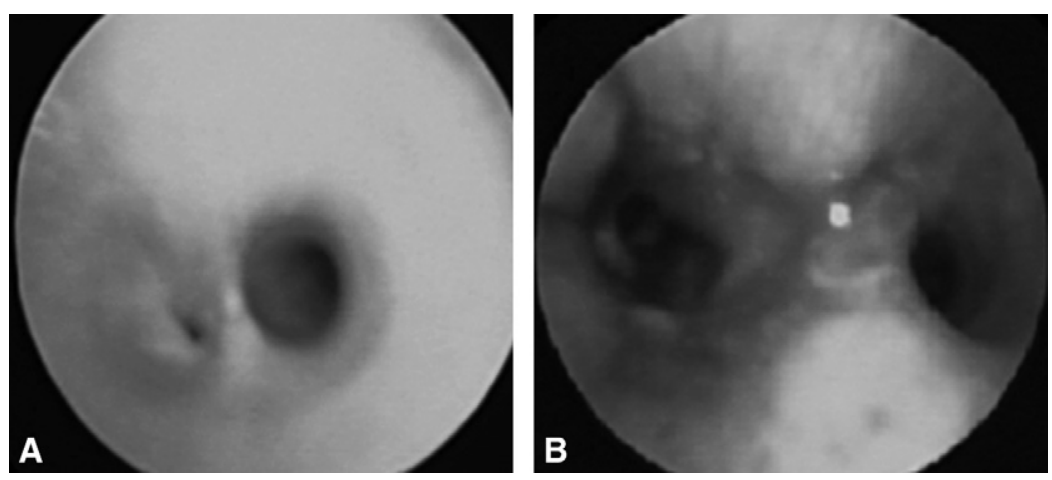

FIGURE 2. Preoperative (A) and postoperative (B) bronchoscopic views of the stenotic right main stem bronchus.

hyperinflation of the middle lobe, no systemic vascular supply, and an associated extrapulmonary anomaly, namely, a horseshoe kidney.

The patient was operated on at 6 months of age via a thoracoscopic approach under split ventilation. Thoracoscopy showed a distended and emphysematous middle lobe. The upper and lower lobes were normal. A right middle lobectomy was carried out under total endoscopic control. The middle lobe bronchus was small in caliber and had a thin wall; no external mass compression or kinking of the bronchus was detected.

Microscopic findings demonstrated a defect in cartilaginous support and a large amount of fibrotic tissue. The lung parenchyma comprised emphysematous and atelectatic areas. The baby progressed well during the follow-up period and remains asymptomatic 13 months after surgery.

\section{Case 3}

A 2-month-old white boy was admitted to the hospital with respiratory distress and cough. He had been delivered vaginally at 41 weeks of gestation with a birth weight of $4100 \mathrm{~g}$. Antenatal ultrasound and chest radiograph at birth, required because of a transitory respiratory distress, were normal. Chest radiograph at 2 months disclosed bilateral hyperlucency, with air trapping being more prominent in the upper left lobe. Three-dimensional computed tomography demonstrated a left upper bronchus stenosis, with a diameter of 0.8 to $1 \mathrm{~mm}$, producing a huge emphysema of the left upper lobe. A thoracoscopic lobectomy was suggested but postponed by the parents.

The patient was finally operated on at the age of 3 months because of an emergency caused by acute respiratory distress related to the large emphysema of the left upper lobe. A left upper lobectomy was performed through a posterior thoracotomy. Macroscopically, the upper lobe bronchus was small in caliber and had a thin and malacic wall. Histologic examination of the specimen confirmed bronchial atresia and alveolar emphysema. The postoperative course was uneventful. The patient remains asymptomatic 14 months after surgery.

\section{Case 4}

A male newborn was referred to our institution with the antenatal diagnosis of a left intrapulmonary mass that was
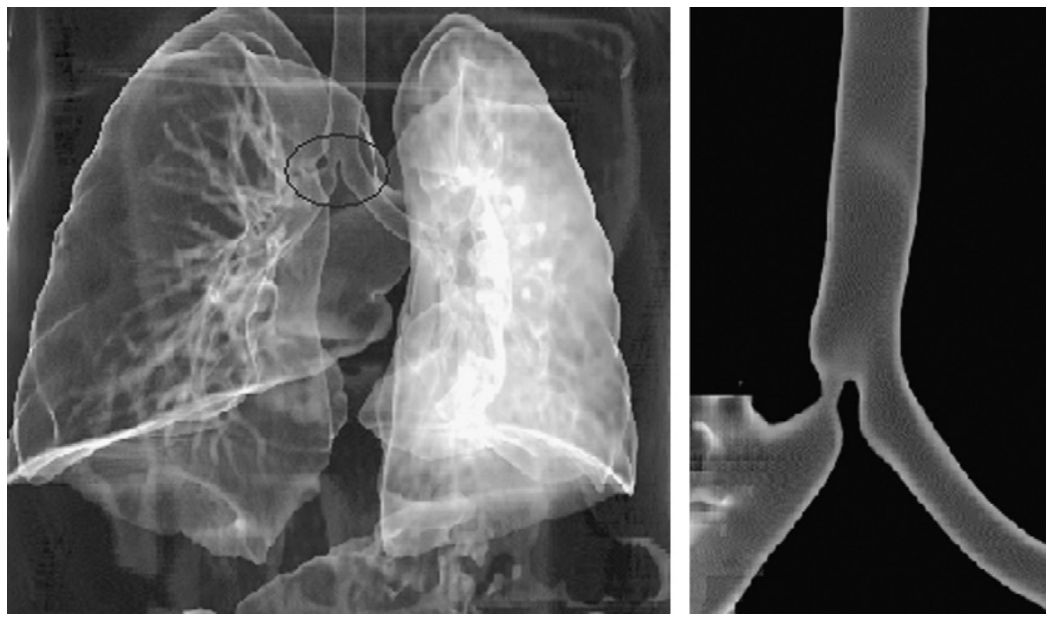

FIGURE 3. Spiral chest computed tomography with MPR demonstrating the right main bronchus stenosis, $5 \mathrm{~mm}$ long with a diameter of 0.8 to $1 \mathrm{~mm}$, producing a large right-lung emphysema. The right lung herniates into the left chest. 




FIGURE 4. Intraoperative image: after cuneiform resection of the stenotic segment, a tension-free anastomosis with interrupted sutures (Vicryl 5/0) was performed.

revealed by routine ultrasound at 22 weeks of gestation. Magnetic resonance imaging (MRI) at 32 weeks of gestation demonstrated a mass, $3 \times 2 \mathrm{~cm}$ in size, in the left lower lobe. A pulmonary sequestration or a congenital cystic adenomatoid malformation was suspected. Chest radiograph and computed tomography after birth confirmed the antenatal findings: hyperlucency and enlargement of the left lower lobe. However, no systemic vascular supply was demonstrated.

The patient was operated on via a totally endoscopic approach under split ventilation at 6 months of age. Thoracoscopy showed a distended and emphysematous inferior lobe. The upper lobe and the rest of the thoracic cavity were normal. A left lower lobectomy was performed. Histologic examination of the specimen showed a markedly stenotic left lower bronchus. The baby progressed well during the follow-up period and remains asymptomatic 9 months after surgery.

\section{DISCUSSION}

Congenital bronchial atresia or stenosis is a rare disorder first reported by Ramsay and Byron in 1953. ${ }^{4}$ The pathogeny was particularly studied by Reid and Simon, who established the criteria for recognition of this entity in 1963..$^{5}$ Although a variety of hypotheses have been proposed as to the embryologic origin of CBAS, there is no conclusive evidence for any of them. To date, one potential explanation is a disturbance in bronchial perfusion analogous to intestinal and esophageal experimental atresia. ${ }^{6}$ Another common theory is a disturbance in bronchial branching occurring on or after the 16th week of the fetal period, when bronchial branching is complete. ${ }^{7}$

Kunisaki and colleagues reviewed the cases of 25 patients who underwent surgical resection of a prenatally diagnosed lung mass. ${ }^{8}$ Bronchial atresia is a common, unrecognized component of prenatally diagnosed congenital cystic adenomatoid malformations (CCAM), bronchopulmonary sequestrations (BPS), congenital lobar emphysemas (CLE), and lesions of mixed pathology. The pathogenesis by which bronchial atresia might lead to different focal developmental malformations of the lung remains unknown. To explain the wide spectrum of some seemingly unrelated lesions, such as level, timing, and degree of bronchial obstruction, Langston has proposed a malformation sequence based on airway obstruction during development. For example, an atretic bronchus early in gestation might favor the formation of a CCAM or a bronchogenic cyst, whereas obstruction later in gestation (eg, 16 to 18 weeks of gestation) might predispose the lung to develop BPS or CLE. ${ }^{9}$

Bronchial obstruction results in enlargement of the peripheral bronchus, mucus accumulation, and emphysematous changes in the peripheral lung. ${ }^{10}$ The air reaches the parenchyma behind the atretic or markedly stenotic bronchus through collateral channels. ${ }^{11}$ This air is not eliminated during expiration because of the check valve mechanism. ${ }^{12} \mathrm{~A}$ mediastinal shift may be noticed, varying with the severity of the emphysema. Other congenital abnormalities that may be associated are pectus excavatum, pericardial defects, anomalous pulmonary venous return, and aplastic lung. ${ }^{13,14}$

Patients with CBAS are usually young adults. Of those adults, 60\% are without symptoms; their anomaly is discovered during a routine chest radiograph. ${ }^{13}$ Otherwise, the patients have symptoms, such as shortness of breath, cough or infection, pneumonopathy, or pneumothorax. ${ }^{6,15}$ CBAS presents differently in children than in adults. It accounts for respiratory embarrassment in infants, as well as recurrent pulmonary infection in children. To the best of our knowledge only a few cases of CBAS with clinical symptoms in the neonatal period have been reported. ${ }^{14}$

Serial ultrasonographic fetal examinations and MRI have made it possible to detect lung masses caused by CBAS in utero. ${ }^{8}$ After birth, spiral contrast computed tomography, with its high spatial resolution, is now the diagnostic method of choice. ${ }^{15}$

The typical pathologic examination of the resected specimen shows a blind-ending or markedly stenotic bronchus associated with distal mucus-filled bronchocele surrounded by hyperinflated lung parenchyma. ${ }^{15}$ More recently, pathologists have determined that the diagnosis of CBAS requires special techniques, including specimen bronchography and microdissection. ${ }^{8}$ Morikawa and colleagues revealed lipid pneumonia in three fourths of their 29 patients, reflecting the clinical aspects of recurrent pneumonia. ${ }^{15}$

Management of central bronchial or tracheal stenosis can be difficult in very small babies because of the small size of the airway. ${ }^{16}$ Two approaches can be used, namely, classical thoracotomy or thoracoscopy. In infants the primary limitation to the use of thoracoscopy is the small working space and the hyperinflated lung, which can obscure the vision; 
the second limitation is the training of the team. A good exposure could be obtained by a single lung ventilation using bronchial blocker or selective intubation of the contralateral bronchus (as in cases 1, 2, and 4); in a newborn, however, these two maneuvers are difficult. Other maneuvers include intrathoracic $\mathrm{CO}_{2}$ insufflation, which will generally offer enough lung compression to provide adequate exposure, or the use of extracorporeal membrane oxygenation. ${ }^{17} \mathrm{Be}-$ cause of their long life expectancy, bronchoplastic reconstructions can salvage normal bronchial and pulmonary tissue; they have obvious advantages for children. Of major importance is that complications like postpneumonectomy syndrome are also avoided. ${ }^{18}$ Bronchoplastic procedures require more experience and skill than other procedures. Precise attention to technical detail, namely, clean transection lines, avoidance of devascularization, minimal handling of the mucosa, and a tension-free anastomosis are the basis of successful bronchoplasty.

Lobectomy (or the technically trickier segmentectomy) is the procedure of choice for the treatment of CBAS. ${ }^{19}$ In children, a thoracoscopic approach is not only associated with decreased postoperative pain and better cosmesis, but it also reduces the psychological, anatomic and functional consequences of thoracotomy, that is, chest wall deformity and scoliosis. ${ }^{20}$

Our cases highlight the successful application of bronchoplasty or thoracoscopic lobectomy in infants affected by CBAS. Elective surgical management during infancy can be achieved with very low morbidity and carries an excellent prognosis in most patients. ${ }^{9}$ Furthermore, early resection of the bronchopulmonary anomaly provides the opportunity for better compensatory lung growth, is associated with a lower rate of recurrent pulmonary infections, and prevents malignant degeneration. ${ }^{8,15}$

\section{References}

1. Suzuki K, Shiratori M, Tanaka H, Itoh T, Oashi K, Harada K, et al. A rare case of pulmonary bronchogenic cyst associated with bronchial atresia in the same lobe. Intern Med. 2003;42:521-4.
2. Psathakis K, Eleftheriou D, Boulas P, Mermigkis C, Tsintiris K. Congenital bronchial atresia presenting as a cavitary lesion on chest radiography: a case report. Cases J. 2009;2:17.

3. Mechoulan A, Podevin G, Paumier A, Philippe H-J, Le Mouel F, Le Vaillant C, et al. Is bronchial atresia prenatal diagnosis possible? Gynécol Obstét Fertil. 2008;36:407-12.

4. Ramsay BH, Byron FX. Mucocele, congenital bronchiectasis, and bronchiogenic cyst. J Thorac Surg. 1953;26:21-30.

5. Simon G, Reid L. Atresia of an apical bronchus of the left upper lobe: report of three cases. Br J Dis Chest. 1963;57:126-32.

6. Ouzidane L, Benjelloun A, el Hajjam M, Ksiver M, Abid A. Segmental bronchial atresia: a case report and a literature review. Eur J Pediatr Surg. 1999;9: 49-52.

7. Kameyama K, Okumura N, Kokado Y, Miyoshi K, Matsuoka K, Nakagawa T. Congenital bronchial atresia associated with spontaneous pneumothorax. Ann Thorac Surg. 2006;82:1497-9.

8. Kunisaki S, Fauza D, Nemes L, Barnewolt C, Estroff J, Kozakewich H, et al. Bronchial atresia: the hidden pathology within a spectrum of prenatally diagnosed lung masses. J Pediatr Surg. 2006;41:61-5.

9. Langston C. New concepts in the pathology of congenital lung malformations. Semin Pediatr Surg. 2003;12:17-37.

10. Haller JA Jr, Tepas JJ 3rd, White JJ, Pickard LR, Rodotham JL. The natural history of bronchial atresia: serial observations of a case from birth to operative correction. J Thorac Cardiovasc Surg. 1980;79:868-72.

11. Voshaar TH. Collateral ventilation. Pneumologie. 2008;62:355-60.

12. Meng RL, Jensik RJ, Faber LP, Matthew GR, Kittle CF. Bronchial atresia. Ann Thorac Surg. 1978;25:184-92.

13. Van Klaveren RJ, Morshuis WJ, Lacquet LK, Cox AL, Festen J, Heystraten FM. Congenital bronchial atresia with regional emphysema associated with pectus excavatum. Thorax. 1992;47:1082-3

14. Seo T, Ando H, Kaneko K, Ono Y, Tainaka T, Sumida W, et al. Two cases of prenatally diagnosed congenital lobar emphysema caused by bronchial atresia. J Pediatr Surg. 2006;41:17-20.

15. Morikawa N, Kuroda T, Honna T, Kitano Y, Fuchimoto Y, Terawaki K, et al. Congenital bronchial atresia in infants and children. J Pediatr Surg. 2005;40: 1822-6.

16. Grillo HC, Wright CD, Vlahakes GJ, MacGillivray TE. Management of congenital tracheal stenosis by means of slide tracheoplasty or resection and reconstruction, with long-term follow-up of growth after slide tracheoplasty. $J$ Thorac Cardiovasc Surg. 2002;123:145-52.

17. Rothenberg SS. Experience with thoracoscopic lobectomy in infants and children. J Pediatr Surg. 2003;38:102-4.

18. Prabhakaran K, Patankar JZ. Bronchoplasty for bronchial stenosis in a neonate: a case report. J Pediatr Surg. 2004;39:e6-8.

19. Okada M, Mimura T, Ikegaki J, Katoh H, Itoh H, Tsubota N. A novel videoassisted anatomic segmentectomy technique: selective segmental inflation via bronchofiberoptic jet followed by cautery cutting. J Thorac Cardiovasc Surg. 2007;133:753-8.

20. Cappeliez S, Stéphane Lenoir S, Validire P, Gossot D. Totally endoscopic lobectomy and segmentectomy for congenital bronchial atresia. Eur J Cardiothorac Surg. 2009;36:222-4. 